\title{
Review
}

\section{Prospective Tests on Biological Models of Acupuncture}

\section{Charles Shang}

\author{
Department of Medicine, Cambridge Health Alliance, Harvard Medical School, 103 Garland Street, Everett, \\ MA 02149, USA
}

\begin{abstract}
The biological effects of acupuncture include the regulation of a variety of neurohumoral factors and growth control factors. In science, models or hypotheses with confirmed predictions are considered more convincing than models solely based on retrospective explanations. Literature review showed that two biological models of acupuncture have been prospectively tested with independently confirmed predictions: The neurophysiology model on the long-term effects of acupuncture emphasizes the trophic and anti-inflammatory effects of acupuncture. Its prediction on the peripheral effect of endorphin in acupuncture has been confirmed. The growth control model encompasses the neurophysiology model and suggests that a macroscopic growth control system originates from a network of organizers in embryogenesis. The activity of the growth control system is important in the formation, maintenance and regulation of all the physiological systems. Several phenomena of acupuncture such as the distribution of auricular acupuncture points, the long-term effects of acupuncture and the effect of multimodal non-specific stimulation at acupuncture points are consistent with the growth control model. The following predictions of the growth control model have been independently confirmed by research results in both acupuncture and conventional biomedical sciences: (i) Acupuncture has extensive growth control effects. (ii) Singular point and separatrix exist in morphogenesis. (iii) Organizers have high electric conductance, high current density and high density of gap junctions. (iv) A high density of gap junctions is distributed as separatrices or boundaries at body surface after early embryogenesis. (v) Many acupuncture points are located at transition points or boundaries between different body domains or muscles, coinciding with the connective tissue planes. (vi) Some morphogens and organizers continue to function after embryogenesis. Current acupuncture research suggests a convergence of the neurophysiology model, the connective tissue model and the growth control model. The growth control model of acupuncture set the first example of a biological model in integrative medicine with significant prediction power.
\end{abstract}

\section{Introduction}

According to the World Health Organization (WHO), a broad definition of acupuncture is the stimulation of certain points on the body (acupuncture points) using needling, moxibustion, electricity, laser or acupressure for therapeutic purposes (1). The standard acupuncture

For reprints and all correspondence: Charles Shang, MD,

Department of Medicine, Cambridge Health Alliance,

Harvard Medical School, 103 Garland Street, Everett, MA 02149,

USA. E-mail: cshang@caregroup.harvard.edu nomenclature published by the WHO listed about 400 acupuncture points and 20 meridians connecting most of the points (2). Results from randomized controlled trials (RCTs) have shown that acupuncture is effective in treating dozens of disorders (1) such as osteoarthritis (3-5), pelvic and back pain (6), neck pain (7), migraine and tension headache $(8,9)$, nausea/vomiting (10) and inflammatory bowel disease (11). Mixed results widely exist in acupuncture research (12) for various reasons such as poor trial design, irregularity of this highly operator-dependent technique and the unique 
biological basis of acupuncture which will be explained later in this article. Many neurohumoral (13-15) mechanical (16) and growth control effects of acupuncture (17) have been observed. Several models of acupuncture mechanism have been proposed. The focus of this article is on the biological models of acupuncture which have been prospectively tested and independently confirmed.

\section{The Observations from Acupuncture Research}

In the mid-70s, the discovery of endorphin induction in acupuncture analgesia and its blockade by naloxone was instrumental in establishing the validity of acupuncture in modern science $(18,19)$. In acupuncture analgesia, the peripheral nervous system has been shown to be crucial in mediating the effect. The analgesia can be abolished if the acupuncture site is affected by postherpetic neuralgia (20) or injection of local anesthetics (21). Different frequencies of electric stimulation in electroacupuncture lead to release of different neuropeptides (13). Electroacupuncture has been shown to release nociceptin and inhibit the reflex-induced increases in blood pressure (15), and increased the synthesis of nitric oxide in mediating the protective effect on gastric mucosa (22).

Since the 1950s, it has been discovered and confirmed with refined techniques (23) that many acupuncture points and meridians have high electrical conductance (24-26) though the results are sometimes mixed (27). High electric conductance of acupuncture points have been successfully used for locating acupuncture points in acupuncture therapy (28). The high electric conductance at acupuncture points is further supported by preliminary finding of high density of gap junctions at the epithelia of the acupuncture points (29-32). Gap junctions are hexagonal protein complexes that form channels between adjacent cells. It is well established in cell biology that gap junctions facilitate intercellular communication and increase electric conductance. High concentrations of nitric oxide and nitric oxide synthase have also been observed at acupuncture points and meridians (33).

\section{Modern Biological Models of Acupuncture}

In the 1970s, the relation between the nervous system and acupuncture alteration of visceral function was explored by examining the cortical evoked potentials, single unit discharges and neurochemistry associated with acupuncture. These studies brought forth the MeridianCortex-Viscera correlation hypothesis which states that: (i) the meridian system is an independent system connected via the nervous system to the cerebral cortex, (ii) it acts through neurohumoral mechanisms (34). A contending model claimed that the meridian system as described in the classic acupuncture literature does not exist and that all the effects of acupuncture are mediated through nervous system $(35,36)$.

Another hypothesis suggested that the network of acupuncture points and meridians is a signal transduction network formed by interstitial connective tissue. Mapping of acupuncture points on human arm showed an $80 \%$ correspondence between the sites of acupuncture points and the location of intermuscular or intramuscular connective tissue planes in postmortem tissue sections (37).

Modern biological models of acupuncture are confronted with the following puzzling facts:

(i) The distribution of acupuncture points: The distribution of acupuncture points is different from the distribution of nerves, blood vessels, lymphatics or connective tissue. For example, an auricle has no important nerves or blood vessels or lymphatics or complex connective tissue planes and no significant physiological function other than sound collection. While the vagus nerve has an auricular branch, this branch has no known important function in modern neuroscience. A search of Medline did not yield any article on the function of the auricular branch of vagus nerve in the past 50 years. The auricle nevertheless has the highest density of acupuncture points. According to the WHO, 43 auricular points have proven therapeutic value (2) which consist of more than $10 \%$ of the acupuncture points of the entire human body. Numerous RCTs have demonstrated the efficacy of auricular acupuncture (38-43) while some results are mixed (12).

(ii) The non-specific activation of acupuncture points: Therapeutic effect of acupuncture has been achieved by a variety of stimuli $(1,10)$ including needling, injection of non-specific chemicals, electricity, temperature variation, laser and pressure. No conventional nerve stimulation technique has such diverse modalities of stimulation. Nonnoxious stimuli such as non-thermal low intensity laser irradiation, which does not cause local nerve excitation (44) or collagen fiber reorganization at acupuncture points, can cause extensive systemic effects (45) and stimulate local cellular calcium oscillation (45) cell proliferation, release of basic fibroblast growth factor, interleukins as well as other growth control effects (46). This suggests that another system other than nervous system mediates the initial signal transduction in acupuncture.

(iii) Transient acupuncture stimulation often causes long lasting effect over weeks or months. For example, two RCTs $(8,9)$ have shown that the relief of migraine headache lasted 1 year after acupuncture treatment - thousands of times longer 
than the physiological half life of endorphin (47) and other common neurotransmitters. Similar long-term benefits of acupuncture have been shown by RCTs on the treatment of shoulder pain (48), chronic low back pain $(49,50)$, primary dysmenorrhea (51), spinal cord injuries (42), urinary urgency (41) and osteoarthritis $(5,52,53)$. This long lasting effect is almost non-existent in conventional therapy using transient mild peripheral nerve stimulation. In conventional nerve stimulation, long lasting effects require long-term stimulation as observed in the effects of opioids, serotonin reuptake inhibitors, sacral nerve stimulation (54) and vagal nerve stimulation (55).

(iv) The existence of acupuncture points. That is, why do stimuli at many acupuncture points cause diverse systemic effects without obvious benefit of survival for normal animals? For example, stimulation at acupuncture points PC6 and ST36 which are at the extremities increases the gastric motility in dogs (56). This is contrary to the fight or flight response and seems to offer no survival benefit to animals. What is the intrinsic function of acupuncture points? How did these acupuncture points come into existence over the course of evolution?

In science, models or hypotheses capable of successful prospective predictions are considered more convincing than models solely based on retrospective explanations or accommodations $(57,58)$. It is therefore important to assess which biological models of acupuncture have been prospectively tested and independently confirmed (i.e. with correct predictions). A literature research in PubMed with full text (Medline) using keywords acupuncture AND (predict* OR corollary) identified 101 articles. Similar search strategy in Chinese medical literature databases including http://www.wanfangdata. com.cn/, http://engine.cqvip.com/ and http://www. chinainfobank.com/identified over 300 articles. Further analysis of the literature and discussion with the experts in this field narrowed down to two biological models $(17,59)$ which have independently confirmed predictions: The neurophysiology model on the long-term effects of acupuncture (59) suggests: (i) The trophic and antiinflammatory effects of acupuncture are important in mediating its long-term effects. (ii) Long-term potentiation and long-term depression are likely involved in acupuncture signal transduction. Its prediction on the peripheral anti-inflammatory effect of endorphin in acupuncture has been confirmed (60). The growth control model first published in the 1980s (61) correctly predicted multiple research results not only in acupuncture, but also in conventional biomedical sciences. It also has shed light on the puzzling observations mentioned above $(17,62)$. This model encompasses the neurophysiology of

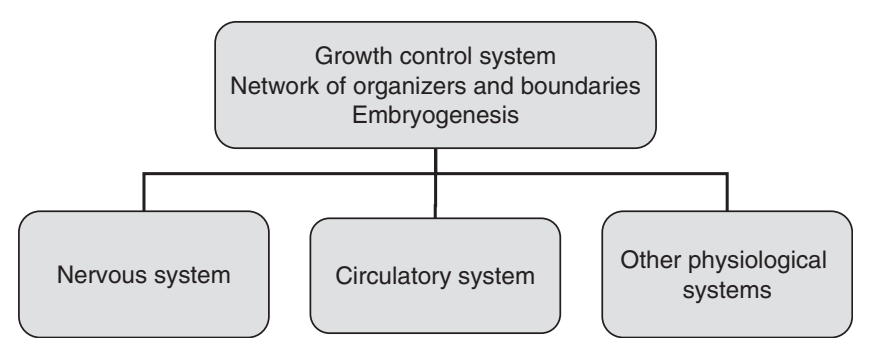

Figure 1. The role of the growth control system. In embryogenesis, the development of organizers precedes the development of other physiological systems. The formation, maintenance and regulation of all the physiological systems are dependent on the activity of the growth control system both during and after embryogenesis. The growth control model of acupuncture suggests that acupuncture points and meridians originate from organizers and growth boundaries, respectively, and play important roles in the maintenance and regulation of all the physiological systems after embryogenesis.

acupuncture (17) and is supported by the research results on connective tissue at acupuncture points $(16,37)$.

\section{The Origin and Function of Acupuncture Points}

It is well known that all the physiological systems, including nervous system, are derived from a system of embryogenesis - a growth control system (63) (Fig. 1). In growth control, the fate of a larger region is frequently controlled by a small group of cells, which is termed an organizing center or organizer (64). A gradient of messenger molecules called morphogens forms around organizers. Organizers have highest (sources) or lowest (sinks) local concentration of morphogens $(64,65)$ and therefore are macroscopic singular points of morphogen gradient field. A singular point is a point of discontinuity. It indicates abrupt transition from one state to another. Small, non-specific perturbations around singular points - organizers can have important systemic effect $(66,67)$. Several lines of evidence suggests that the bioelectric field interacts with morphogens and growth factors, and guides morphogenesis $(68,69)$. The growth and migration of a variety of cells are sensitive to electric fields of physiological strength $(70,71)$. Organizers and acupuncture points share several common features: Both commonly distribute at the extreme points of surface curvature $(17,61,62)$ and are activated by non-specific stimuli $(61,67)$. Both are associated with bioelectric field (17). The growth control model therefore suggested that acupuncture points originate from organizers $(17,61)$.

\section{Confirmed Predictions on Organizers and Morphogens}

Based on the connection between acupuncture points and organizers, the growth control model predicted that organizers have high electric conductance, high electric 


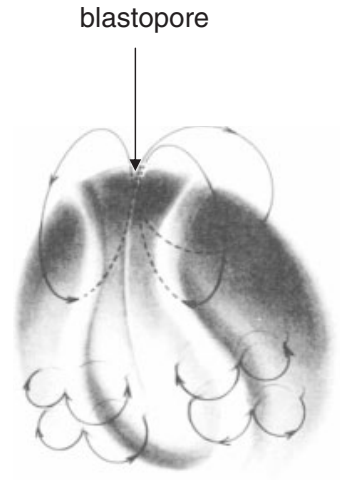

Figure 2. Electric currents traversing an embryo (Source: Shi and Borgens, Dev Dynamics 1996;202:102. Courtesy of John Wiley \& Sons). The blastopore, a classic organizer, has high electric conductance and current density. A steady blastopore current persists after early embryogenesis. The electric fields polarize the embryo and serve as cues for morphogenesis. These results confirmed earlier predictions. (Shang, Am J Chin Med 1989;17:119-27).

current density and high density of gap junctions $(17,61)$. These predictions on organizers have been independently confirmed: Organizers such as blastopore (Fig. 2) and zone of polarizing activity have high electric conductance, high current density (72) and high density of gap junctions (73-76). Multi-cellular organisms maintain regular form and function despite constant replacement of cells, intra-cellular components and extracellular matrix. Without growth control, this constant regeneration is prone to structural disintegration and degeneration into various tumors. The growth control model predicted that organizers and morphogens partially retain their regulatory function after embryogenesis $(17,61)$. This prediction has also been independently confirmed: Morphogens such as retinoic acid, Wnt, bone morphogenetic protein and Hedgehog as well as some organizers continue to exist and function in adults after embryogenesis (77-81).

\section{Confirmed Predictions on Acupuncture}

One corollary from the growth control model is that acupuncture has extensive growth control effects which have been confirmed: Acupuncture has been shown to regulate various growth factors and growth control genes. It can induce vascular endothelial growth factor (82) and basic fibroblast growth factor (83) during brain ischemia. It also induces glial cell line-derived neurotrophic factor (84) and expression of the c-fos proto-oncogene $(85,86)$. Acupuncture regulates the expression of $\mathrm{Bcl}-2$ (87), Bax, fas and FasL proteins which are involved in apoptosis signaling. Acupuncture inhibits the apoptosis of intestinal epithelial cells in inflammatory bowel disease of rats (88) and enhances proliferation of CD8 + lymphocytes (89), reduces nerve growth factor in polycystic ovaries $(90,91)$ and reduces IL-6 expression and proliferation of osteoclasts (92). The neuro-humoral factors induced by acupuncture such as endorphins, nitric oxide and serotonin also have growth-control effects $(93,94,95)$. In RCTs, acupuncture has shown efficacy in treating growth-control-related disorders including spinal cord injuries (38) and low sperm quality $(96,97)$.

\section{Growth Control System as Foundation of Pathophysiology}

A growth control system originates from a network of organizers (98). In embryogenesis, the development of organizers precedes the development of other physiological systems $(17,64)$. The formation, maintenance and regulation of all the physiological systems are dependent on the activity of the growth control system. Growth control is a primary function of all multi-cellular organisms. The evolutionary origin of the growth control system likely preceded all the other physiological systems. Its genetic blueprint served as a template from which the newer systems evolved. Consequently, it overlaps and interacts with other systems but is not merely part of the nervous system, immune system or circulatory system. The growth control signal transduction is embedded in the activity of the function-based physiological systems: The regulation of many neural, circulatory, immune processes and related disorders are mediated through growth control mechanisms such as hypertrophy, hyperplasia, atrophy, apoptosis with shared messenger molecules including morphogens $(77,81,95,99)$ and common signal transduction pathways involving growth control genes such as proto-oncogenes (100-102).

\section{The Non-specific Stimulation and the Long-term Effects of Acupuncture}

Based on the growth control model, acupuncture points and organizers are singular points and therefore prone to non-specific perturbation. The long lasting systemic effects of acupuncture can be achieved by non-specific stimuli as mentioned earlier. Similarly, long lasting growth control activities of organizers have been induced by various stimuli such as mechanical injury and injection of non-specific chemicals (67). Based on the growth control model, acupuncture effect is a byproduct of the growth control network. Stimulating organizersacupuncture points can not only cause transient modulation of neurotransmission, but also alter the growth control signal transduction in various systems - leading to long-term effects (17). 


\section{The Distribution of Acupuncture Points and Organizers}

Organizers are at the extreme points of curvature on the body surface such as the locally most convex points (e.g. apical ectodermal ridge and other growth tips) or concave or saddle points (e.g. zone of polarizing activity) $(17,103)$. Similarly, almost all the extreme points of the body surface curvature are acupuncture points. For example, the convex points include EX-UE11 Shixuan (finger tips), EX-LE12 Qiduan (toe tips), ST17 Ruzhong (tip of nipple), ST42 Chongyang, (the convex, palpable point of arteria dorsalis pedis) and GV25 Suliao (nose tip). The concave points include TE3 Zhongzhu (the concave point between the fourth and fifth metacarpal), KI1 Yongquan (at the concave point of the sole), GB20 Fengchi (the concave point below occipital bone, between upper ends of sternocleidomastoid and trapezius), BL40 Weizhong (midpoint of the transverse crease of the popliteal fossa), HT1 Jiquan (the most concave point of axilla), BL1 Jingming (at the concave point above medial canthus) and CV8 Shenque (navel). Based on growth control model, the extreme points of surface curvature are associated with organizers - acupuncture points. The auricle obviously has the most convoluted surface morphology of the human body. Therefore, it has the highest density of extreme points of surface curvature and is expected to have the highest density of organizers-acupuncture points. Auricle exemplifies the interconnection of growth control: Auricular morphology is a sentinel of malformation in other organs. Auricular malformation has been observed in numerous malformation syndromes. It is recommended in a standard textbook of pediatrics that any auricular anomaly should initiate a search for malformations in other parts of the body (104).

\section{The Origin of Meridians}

The growth control model suggests that the discontinuity or abrupt transition in growth control not only exists at organizers but also along boundaries $(17,61)$. The growth control boundaries or folds between different structures are also called separatrices in mathematics and often connect singular points - organizers. The model predicted that growth control boundaries have high electric conductance and high density of gap junctions - just as the meridians in acupuncture which likely originate from growth control boundaries. These predictions have been confirmed: As embryogenesis progresses, high density gap junctions become restricted at discrete boundaries, leading to the subdivision of the embryo into communication compartment domains $(105,106)$. Increasing or decreasing the gap junctions can cause various developmental defects (107) such as spina bifida (108). These high electric conductance boundaries are likely major pathways of bioelectric currents. Organizers are known to locate at boundaries between different structures (109). The growth control model suggests that meridians originate from separatrices-boundaries in growth control and form an underdifferentiated $(17,61)$, interconnected cellular network that regulates growth and physiology. In consistence with the prediction of underdifferentiation of the meridian system and growth control system, it has been observed that the most apical part of folds of embryo remain undifferentiated in morphogenesis (110), including organizers such as apical ectodermal ridge (111). As predicted by the growth control model, singular point and separatrix have important roles in morphogenesis $(112,113)$. Growth control boundaries/separatrices are similar to organizers in controlling growth and pattern formation with morphogen gradient (114). Many acupuncture points are located at boundaries between different body domains or muscles, coinciding with the connective tissue planes which connect adjacent body domains or muscles $(16,37,115)$.

\section{Conclusion}

Current acupuncture research suggests a convergence of the neurophysiology model, the connective tissue model and the growth control model. The growth control model of acupuncture set the first example of a biological model in integrative medicine with significant prediction power across multiple disciplines. The following predictions of the growth control model have been independently confirmed by research results in both acupuncture and conventional biomedical sciences: (i) Acupuncture has extensive growth control effects. (ii) Singular point and separatrix have important roles in morphogenesis. (iii) Organizers have high electric conductance, high current density and high density of gap junctions. (iv) A high density of gap junctions is distributed as separatrices or boundaries at body surface after early embryogenesis. (v) Many acupuncture points are located at transition points or boundaries between different body domains or muscles, coinciding with the connective tissue planes. (vi) Some morphogens and organizers continue to function after embryogenesis. The growth control model has also shed light on several puzzling phenomena of acupuncture such as the distribution of auricular acupuncture points, the long-term effects of acupuncture and the effect of multimodal non-specific stimulation at acupuncture points.

\section{Future Directions}

Acupuncture is becoming increasingly a multidisciplinary research field requiring the collaboration among developmental biologists, biophysicists, engineers, cell biologists, 
neurobiologists, mathematicians and clinicians to achieve further advances.

(i) The structure and cell differentiation at acupuncture points as well as the neurophysiology and growth control signal transduction involved in different modalities of acupuncture should be further delineated.

(ii) Application of singularity theory is important in integrative medicine, developmental biology as well as systems biology-requiring the collaboration between mathematicians and other biomedical researchers. Manipulating the singular pointsorganizers of the growth control system may be a convenient way of activating intrinsic stem cells as evident from the improvement of sperm quality after acupuncture $(96,97)$.

(iii) As the growth control model predicts the growth control activity at acupuncture points/extreme points of surface curvature at body surface after embryogenesis, residual morphogen gradient may still exist at these points and may be detectable by probing morphogen candidates such as Hedgehog, Wnt and TGF-beta families. Certain morphogen gradient distributes along boundaries (116). This pattern may persist after embryogenesis into adulthood and coincides with meridians.

(iv) Mapping of the growth control system and the dynamics of its electromagnetic field with high resolution techniques such as the superconducting quantum interference device (SQUID) and atomic magnetometer (117) 'by biophysicists and biomedical engineers'. The growth control model predicts that the singular points and separatrices of the bioelectric field in growth control correlate with the acupuncture points and meridians, respectively.

(v) The growth control model suggests that techniques involving the stimulation of the growth control system such as acupuncture can activate the growth control activity of an organism and improve its structure and function at a more fundamental level than symptomatic relief (17). In growth control, the change in electric field precedes morphologic change and manipulation of the electric field can affect the change $(70,118)$. Development of the techniques of detecting and manipulating the electric field may enable the diagnosis and treatment of a pathologic process at the early signal transduction stage prior to the anatomical or morphological change.

(vi) The growth control model suggests that apparently unrelated acupuncture points are not exactly 'placebo' points. The more acupuncture points are used as placebo points in a RCT, the more likely that some systemic effects will be resulted
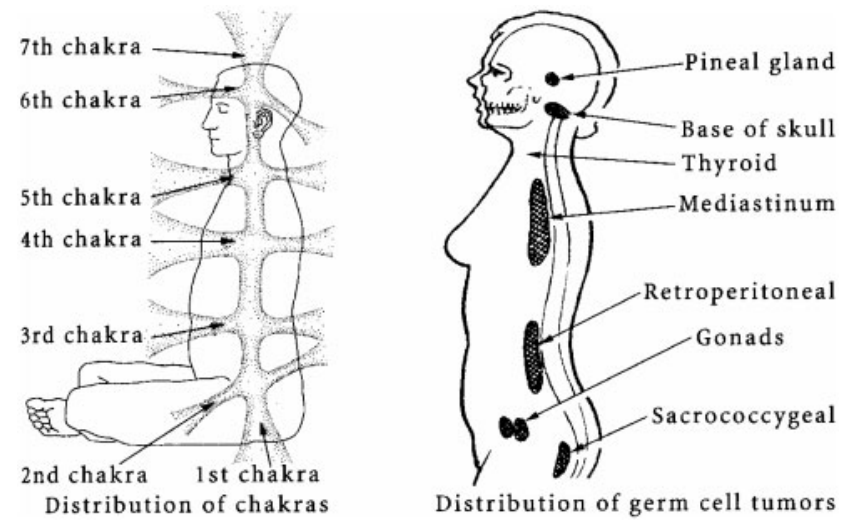

Figure 3. Just as the distribution of pheochromocytoma correlates with the distribution of sympathetic ganglions, the distribution of germ cell tumors correlates with undifferentiated cells in human body which are likely to be involved in the regulation of growth control and physiology as part of the 'inner meridian system'. This distribution also correlates well with the chakra system used in yoga and acupuncture, suggesting a unified structural basis for chakra system and meridian system. Figure modified from: Govan ADT, MacFarlane PS, Callander R et al (1995) Pathology illustrated, 4the edn, Churchill Livingstone, London, p150 and form: Stux (1997) Bascis of acupuncture, 4th edn. Springer Berlin p287 Courtesy of Churchill Livingstone and Dr. Gabriel Stux.

from the 'placebo' treatment. The self-regulatory effect of acupuncture will be difficult to predict when the patients have multiple comorbidities and many acupuncture points are used. Subtle, 'sham' stimulation at acupuncture points can be effective due to the response of the acupuncture points to non-specific stimuli. These reasons may contribute to the mixed results in RCTs on acupuncture.

(vii) The growth control model suggests that the distribution of growth control system is related to both internal and external structures. Acupuncture points which are not at obvious extreme points of surface curvature or meridians which are not at obvious surface boundaries may be vestigial or related to internal structures. Intrinsic stem cells are likely part of the underdifferentiated growth control network. The germ cell is one of the least differentiated cells and also a type of stem cell - similar to the embryonic stem cell in its ability to differentiate into all three germ layers. The distribution pattern of intrinsic germ cells can be deduced based on the fact that the distribution pattern of primary tumors reflects the distribution of their normal counterpart. The primary germ cell tumors (119) have a midline and para-axial distribution pattern which spans from the sacrococcygeal region to pineal gland. It appears to concentrate at 7 locations: sacrococcygeal region, gonads, retroperitoneum, thymus, thyroid, (120) suprasellar region and pineal gland, similar to the distribution of major charkas (Fig. 3). This pattern reflects the distribution 
pattern of intrinsic germ cells which are likely to be highly inter-connected in a normal state, e.g. via gap junctions (121), and provide important regulatory functions $(56,122)$. This also suggests a hierarchy in the degree of cell differentiation and function in the growth control system which is likely to be the unified biological basis of meridian system and chakra system.

\section{Acknowledgement}

I thank Steven K. H. Aung, Zang-Hee Cho, Yuenan Cui, Richard Hammerschlag, Maria do Desterro Leiros, Michael Levin, Colin McCaig, Marc S. Micozzi, Margaret Naeser, Vitaly Napadow, Stig Ollmar, Rosa N. Schnyer, Neil D. Theise, San Wan, Peter Wayne, Raimond Wong, Seung-Schik Yoo and many others for their input.

\section{References}

1. World Health Organization. Acupuncture: Review and Analysis of Reports on Controlled Clinical Trials. Geneva: WHO, 2002.

2. World Health Organization. A Proposed Standard International Acupuncture Nomenclature: Report of a WHO Scientific Group. Geneva: World Health Organization, 1991.

3. Osiri M, Welch V, Brosseau L, Shea B, McGowan J, Tugwell P, et al. Transcutaneous electrical nerve stimulation for knee osteoarthritis. Cochrane Database Syst Rev 2000:CD002823.

4. Kwon YD, Pittler MH, Ernst E. Acupuncture for peripheral joint osteoarthritis: a systematic review and meta-analysis. Rheumatology 2006;45:1331-7.

5. Berman BM, Lao L, Langenberg $\mathrm{P}$, Lee WL, Gilpin AM, Hochberg MC. Effectiveness of acupuncture as adjunctive therapy in osteoarthritis of the knee: a randomized, controlled trial. Ann Intern Med. 2004;141:901-10.

6. Young G, Pennick VE. Interventions for preventing and treating pelvic and back pain in pregnancy. Cochrane Database Syst Rev 2007:CD001139.

7. Trinh KV, Graham N, Gross A, Goldsmith CH, Wang E, Cameron ID, et al. Acupuncture for neck disorders. Cochrane Database Syst Rev 2006;3:CD004870.

8. Vincent CA. A controlled trial of the treatment of migraine by acupuncture. Clin J Pain 1989;5:305-12.

9. Vickers AJ, Rees RW, Zollman CE, McCarney R, Smith CM, Ellis N. Acupuncture for chronic headache in primary care: large, pragmatic, randomised trial. $\mathrm{Br}$ Med $J$ 2004;328:744-7.

10. Vickers AJ. Can acupuncture have specific effects on health? A systematic review of acupuncture antiemesis trials. $J R$ Soc Med 1996;89:303-11.

11. Joos S, Brinkhaus B, Maluche C, Maupai N, Kohnen R, Kraehmer N, et al. Acupuncture and moxibustion in the treatment of active Crohn's disease: a randomized controlled study. Digestion 2004;69:131-9.

12. Kim YS, Jun H, Chae Y, Park HJ, Kim BH, Chang IM, et al. The practice of Korean medicine: an overview of clinical trials in acupuncture. Evid Based Complement Alternat Med 2005;2:325-52.

13. Han JS. Acupuncture: neuropeptide release produced by electrical stimulation of different frequencies. Trends Neurosci 2003;26:17-22.

14. Han JS. Opioid and antiopioid peptides: a model of Yin-Yang balance in acupuncture mechanism of pain modulation. In: Stux G, Hammerschlag R (eds). Clinical Acupuncture: Scientific Basis. Berlin: Springer-Verlag; 2000, 51-68.

15. Crisostomo MM, Li P, Tjen-A-Looi SC, Longhurst JC. Nociceptin in rVLM mediates electroacupuncture inhibition of cardiovascular reflex excitatory response in rats. J Appl Physiol 2005;98:2056-63.

16. Langevin HM, Churchill DL, Wu J, Badger GJ, Yandow JA, Fox JR, et al. Evidence of connective tissue involvement in acupuncture. FASEB J 2002;16:872-4.

17. Shang C. Electrophysiology of growth control and acupuncture. Life Sci 2001;68:1333-42.

18. Pomeranz B, Chiu D. Naloxone blocks acupuncture analgesia and causes hyperalgesia: endorphin is implicated. Life Sci 1976;19:1757-62.

19. Mayer DJ, Price DD, Raffii A. Antagonism of acupuncture analgesia in man by the narcotic antagonist naloxone. Brain Res 1977;121:368-72.

20. Bowsher D. Mechanisms of acupuncture. In: Filshie J, White A (eds). Medical Acupuncture. Edinburgh: Churchill Livingston, 1998; 69-80.

21. Chiang CY, Chang CT. Peripheral afferent pathway for acupuncture analgesia. Scientia Sinica 1973;16:210-7.

22. Xu GS, Wang ZJ, Zhu SL, Chen QZ, Zhang DQ. Nitric oxide participates in protective effect of acupuncture on gastric mucosal damages in rats. World $J$ Gastroenterol 1996;2:58-9.

23. Colbert AP, Yun J, Larsen A, Edinger T, Gregory WL, Thong T. Skin impedance measurements for acupuncture research: development of a continuous recording system. Evid Based Complement Alternat Med 2007; 10.1093/ecam/nem060.

24. Comunetti A, Laage S, Schiessl N, Kistler A. Characterisation of human skin conductance at acupuncture points. Experientia 1995;51:328-31.

25. Saku K, Mukaino Y, Ying H, Arakawa K. Characteristics of reactive electropermeable points on the auricles of coronary heart disease patients. Clin Cardiol 1993;16:415-9.

26. Oleson TD, Kroenig RJ, Bresler DE. An experimental evaluation of auricular diagnosis: the somatotopic mapping of musculoskeletal pain at acupuncture points. Pain 1980;8:217-29.

27. Ahn AC, Wu J, Badger GJ, Hammerschlag R, Langevin HM. Electrical impedance along connective tissue planes associated with acupuncture meridians. BMC Complement Alternat Med 2005;5:10.

28. Shiraishi T, Onoe M, Kageyama T, Sameshima Y, Kojima T, Konishi S, et al. Effects of auricular acupuncture stimulation on nonobese, healthy volunteer subjects. Obes Res 1995;3:667S-73S.

29. Mashanskii VF, Markov IuV, Shpunt VKh, Li SE, Mirkin AS. Topography of the gap junctions in the human skin and their possible role in the non-neural signal transduction. Arkh Anat Gistol Embriol 1983;84:53-60.

30. Cui H-M. Meridian system - specialized embryonic epithelial conduction system. Shanghai J Acupunct 1988;3:44-5.

31. Fan JY. The role of gap junctions in determining skin conductance and their possible relationship to acupuncture points and meridians. Am J Acupunct 1990;18:163-70.

32. Zheng CH, Huang GY, Zhang MM, Xiao YL. Experimental study on expression of connexin 43 in meridians of rats. Zhongguo Zhen Jiu 2005;25:629-32.

33. Ma SX. Enhanced nitric oxide concentrations and expression of nitric oxide synthase in acupuncture points/meridians. J Altern Complement Med 2003;9:207-15.

34. Chang HC, Xie YK, Wen YY, Zhang SY, Qu JH, Lu WJ. Further investigation on the hypothesis of meridian-cortex-viscera interrelationship. Am J Chin Med 1983;11:5-13.

35. Ulett GA. Beyond Yin and Yang: How Acupuncture Really Works. St Louis, MO: Warren H. Green, Inc., 1992.

36. Mann F. A new system of acupuncture. In: Filshie J, White A (eds). Medical Acupuncture. Edinburgh: Churchill Livingston; 1998, 63.

37. Langevin HM, Yandow JA. Relationship of acupuncture points and meridians to connective tissue planes. Anat Rec (New Anat) 2002;269:257-65.

38. Barker R, Kober A, Hoerauf K, Latzke D, Adel S, Kain ZN, et al. Out-of-hospital auricular acupressure in elder patients with hip fracture: a randomized double-blinded trial. Acad Emerg Med 2006;13:19-23.

39. Usichenko TI, Dinse M, Hermsen M, Witstruck T, Pavlovic D, Lehmann Ch. Auricular acupuncture for pain relief after total hip arthroplasty - a randomized controlled study. Pain 2005;114:320-7. 
40. Sator-Katzenschlager SM, Scharbert G, Kozek-Langenecker SA, Szeles JC, Finster G, Schiesser AW, et al. The short- and long-term benefit in chronic low back pain through adjuvant electrical versus manual auricular acupuncture. Anesth Analg 2004:98:1359-64.

41. Ricci L, Minardi D, Romoli M, Galosi AB, Muzzonigro G. Acupuncture reflexotherapy in the treatment of sensory urgency that persists after transurethral resection of the prostate: a preliminary report. Neurourol Urodyn 2004;23:58-62.

42. Wong AM, Leong CP, Su TY, Yu SW, Tsai WC, Chen CP. Clinical trial of acupuncture for patients with spinal cord injuries. Am J Phys Med Rehabil 2003;82:21-7.

43. Bier ID, Wilson J, Studt P, Shakleton M. Auricular acupuncture, education, and smoking cessation: a randomized, sham-controlled trial. Am J Public Health 2002;92:1642-7.

44. Jarvis D, MacIver MB, Tanelian DL. Electrophysiologic recording and thermodynamic modeling demonstrate that helium-neon laser irradiation does not affect peripheral Adelta- or C-fiber nociceptors. Pain 1990;43:235-42.

45. Whittaker P. Laser acupuncture: past, present, and future. Lasers Med Sci 2004;19:69-80.

46. Yu HS, Wu CS, Yu CL, Kao YH, Chiou MH. Helium-neon laser irradiation stimulates migration and proliferation in melanocytes and induces repigmentation in segmental-type vitiligo. $J$ Invest Dermatol 2003;120:56-64.

47. Foley KM, Kourides IA, Inturrisi CE, Kaiko RF, Zaroulis CG, Posner JB, et al. Endorphin: analgesic and hormonal effects in humans. Proc Natl Acad Sci USA. 1979;76:5377-81.

48. Guerra de Hoyos JA, Andres Martin Mdel C, Bassas y Baena de Leon E, Vigara Lopez M, Molina Lopez T, Verdugo Morilla FA, et al. Randomised trial of long term effect of acupuncture for shoulder pain. Pain 2004;112:289-98.

49. Sator-Katzenschlager SM, Scharbert G, Kozek-Langenecker SA, Szeles JC, Finster G, Schiesser AW, et al. The short- and longterm benefit in chronic low back pain through adjuvant electrical versus manual auricular acupuncture. Anesth Analg 2004:98:1359-64.

50. Carlsson CP, Sjölund BH. Acupuncture for chronic low back pain: a randomized placebo-controlled study with long-term follow-up. Clin J Pain 2001;17:296-305.

51. Helms JM. Acupuncture for the management of primary dysmenorrhea. Obstet Gynecol 1987;69:51-6.

52. Witt CM, Jena S, Brinkhaus B, Liecker B, Wegscheider K, Willich SN. Acupuncture in patients with osteoarthritis of the knee or hip: a randomized, controlled trial with an additional nonrandomized arm. Arthritis Rheum 2006;54 3485-93.

53. Stener-Victorin E, Kruse-Smidje C, Jung K. Comparison between electro-acupuncture and hydrotherapy, both in combination with patient education and patient education alone, on the symptomatic treatment of osteoarthritis of the hip. Clin $J$ Pain 2004:20:179-85

54. Janknegt RA, Janknegt RA, Hassouna MM, Hassouna MM, Siegel SW, Siegel SW, et al. Long-term effectiveness of sacral nerve stimulation for refractory urge incontinence. Eur Urol 2001;39:101-6.

55. Schachter SC. Vagus nerve stimulation therapy summary: five years after FDA approval. Neurology 2002;59:S15-20.

56. Qian L, Peters LJ, Chen JD. Effects of electroacupuncture on gastric migrating myoelectrical complex in dogs. Dig Dis Sci 1999;44:56-62.

57. Lipton P. Testing hypotheses: prediction and prejudice. Science 2005:307:219-21.

58. Desbiens NA. More support for prediction. 2005; http://www.scien cemag.org/cgi/eletters/307/5707/219

59. Carlsson C. Acupuncture mechanisms for clinically relevant longterm effects-reconsideration and a hypothesis. Acupunct Med 2002;20:82-99.

60. Kim HW, Roh DH, Yoon SY, Kang SY, Kwon YB, Han HJ, et al. The anti-inflammatory effects of low- and high-frequency electroacupuncture are mediated by peripheral opioids in a mouse air pouch inflammation model. $J$ Altern Complement Med $2006 ; 12: 39-44$
61. Shang C. Singular point, organizing center and acupuncture point. Am J Chin Med 1989;17:119-27.

62. Shang C. The past, present and future of the meridian system research. In: Stux G, Hammerschlag R (eds). Clinical Acupuncture: Scientific Basis. Berlin: Springer-Verlag, 2000;69-82.

63. Bryant PJ, Simpson P. Intrinsic and extrinsic control of growth in developing organs. Quart Rev Biol 1984;59:387-415.

64. Meinhardt H. Models of Biological Pattern Formation. London: Academic, 1982, 20.

65. Niehrs C. Regionally specific induction by the Spemann-Mangold organizer. Nat Rev Genet 2004;5:425-34.

66. Winfree AT. The Geometry of Biological Time. New York: Springer-Verlag, 1980, 71

67. Toivonen S. Regionalization of the embryo. In: Nakamura O, Toivonen S (eds). Organizer - A Milestone of a Half- Century from Spemann. Amsterdam: Elsevier, 1978, 132.

68. McCaig CD, Zhao M. Physiological electrical fields modify cell behaviour. Bioessays 1997;19:819-26.

69. Marx JL. Electric currents may guide development. Science 1981;211:1147-9.

70. Huttenlocher A, Horwitz AR. Wound healing with electric potential. $N$ Engl J Med 2007;356:303-4.

71. Erickson CA. Morphogenesis of the neural crest. In: Browder LW (ed). Developmental Biology, Vol. 2. New York: Plenum; 1985, 528.

72. Hotary KB, Robinson KR. Endogenous electrical currents and voltage gradients in Xenopus embryos and the consequences of their disruption. Dev Biol 1994;166:789-800.

73. Laird DW, Yancey SB, Bugga L, Revel JP. Connexin expression and gap junction communication compartments in the developing mouse limb. Dev Dyn 1992;195:153-61.

74. Yancey SB, Biswal S, Revel JP. Spatial and temporal patterns of distribution of the gap junction protein connexin43 during mouse gastrulation and organogenesis. Development 1992;114:203-12.

75. Coelho CN, Kosher RA. A gradient of gap junctional communication along the anterior-posterior axis of the developing chick limb bud. Dev Biol 1991;148:529-35.

76. Meyer RA, Cohen MF, Recalde S, Zakany J, Bell SM, Scott WJ, et al. Developmental regulation and asymmetric expression of the gene encoding Cx43 gap junctions in the mouse limb bud. Dev Genet 1997;21:290-300.

77. Rosendahl A, Pardali E, Speletas M, Ten Dijke P, Heldin CH, Sideras P. Activation of bone morphogenetic protein/Smad signaling in bronchial epithelial cells during airway inflammation. Am J Respir Cell Mol Biol 2002;27:160-9.

78. Maden M. The role of retinoic acid in embryonic and postembryonic development. Proc Nutr Soc 2000;59:65-73.

79. Farquharson C, Jefferies D, Seawright E, Houston B. Regulation of chondrocyte terminal differentiation in the postembryonic growth plate: the role of the PTHrP-Indian hedgehog axis. Endocrinology 2001:142:4131-40.

80. Kishimoto J, Burgeson RE, Morgan BA. Wnt signaling maintains the hair-inducing activity of the dermal papilla. Genes Dev 2000;14:1181-5.

81. Miano JM, Topouzis S, Majesky M, Olson EN. Retinoid receptor expression and all-trans retinoic acid-mediated growth inhibition in vascular smooth muscle cells. Circulation 1996;93:1886-95.

82. Wang SJ, Omori N, Li F, Jin G, Hamakawa Y, Sato K, et al. Functional improvement by electro-acupuncture after transient middle cerebral artery occlusion in rats. Neurol Res 2003;25:516-21.

83. Ou YW, Han L, Da CD, Huang YL, Cheng JS. Influence of acupuncture upon expressing levels of basic fibroblast growth factor in rat brain following focal cerebral ischemiaevaluated by time-resolved fluorescence immunoassay. Neurol Res 2001;23:47-50.

84. Liang XB, Luo Y, Liu XY, Lu J, Li FQ, Wang Q, et al. Electroacupuncture improves behavior and upregulates GDNF mRNA in MFB transected rats. Neuroreport 2003;14:1177-81.

85. Pan B, Castro-Lopes JM, Coimbra A. Activation of anterior lobe corticotrophs by electroacupuncture or noxious stimulation in the anaesthetized rat, as shown by colocalization of Fos protein with ACTH and beta-endorphin and increased hormone release. Brain Res Bull 1996;40:175-82. 
86. Lee JH, Beitz AJ. The distribution of brain-stem and spinal cord nuclei associated with different frequencies of electroacupuncture analgesia. Pain 1993;52:11-28.

87. Zhang Y, Wu GC, He QZ, Cao XD. Effect of morphine and electro-acupuncture (EA) on apoptosis of thymocytes. Acupunct Electrother Res 2000;25:17-26.

88. Wu HG, Gong X, Yao LQ, Zhang W, Shi Y, Liu HR, et al. Mechanisms of acupuncture and moxibustion in regulation of epithelial cell apoptosis in rat ulcerative colitis. World $J$ Gastroenterol 2004;10:682-8.

89. Chen Y, Zhao C, Chen H, Qin H, Fang F. Effects of "moxibustion serum" on proliferation and phenotypes of tumor infiltrating lymphocytes. J Tradit Chin Med 2003;23:225-9.

90. Stener-Victorin E, Lundeberg T, Waldenstrom U, Manni L, Aloe L, Gunnarsson S, et al. Effects of electro-acupuncture on nerve growth factor and ovarian morphology in rats with experimentally induced polycystic ovaries. Biol Reprod 2000;63:1497-503.

91. Bai YH, Lim SC, Song CH, Bae CS, Jin CS, Choi BC, et al. Electro-acupuncture reverses nerve growth factor abundance in experimental polycystic ovaries in the rat. Gynecol Obstet Invest 2004;57:80-5.

92. Liu X, Shen L, Wu M, Wu B, Gao L, Hu W, et al. Effects of acupuncture on myelogenic osteoclastogenesis and IL-6 mRNA expression. J Tradit Chin Med 2004;24:144-8.

93. Kishi H, Mishima HK, Sakamoto I, Yamashita U. Stimulation of retinal pigment epithelial cell growth by neuropeptides in vitro. Curr Eye Res 1996;15:708-13.

94. Pakala R, Benedict CR. Effect of serotonin and thromboxane A2 on endothelial cell proliferation: effect of specific receptor antagonists. J Lab Clin Med 1998;131:527-37.

95. Voelker CA, Miller MJ, Zhang XJ, Eloby-Childress S, Clark DA, Pierce MR. Perinatal nitric oxide synthase inhibition retards neonatal growth by inducing hypertrophic pyloric stenosis in rats. Pediatr Res 1995;38:768-74.

96. Siterman S, Eltes F, Wolfson V, Zabludovsky N, Bartoov B. Effect of acupuncture on sperm parameters of males suffering from subfertility related to low sperm quality. Arch Androl 1997:39 155-61.

97. Pei J, Strehler E, Noss U, Abt M, Piomboni P, Baccetti B, et al. Quantitative evaluation of spermatozoa ultrastructure after acupuncture treatment for idiopathic male infertility. Fertil Steril 2005;84:141-7.

98. Rives AW, Galitski T. Modular organization of cellular networks. Proc Natl Acad Sci USA 2003;100:1128-33.

99. Lee CH, Whiteman AL, Murphy CJ, Barney NP, Taylor PB, Reid TW. Substance P, insulin like growth factor 1 , and surface healing. Arch Ophthalmol 2002;120:215-7.

100. Baldwin AS Jr. The NF-kappa B and I kappa B proteins: new discoveries and insights. Annu Rev Immunol 1996;14:649-83.

101. Bailey CH, Bartsch D, Kandel ER. Toward a molecular definition of long-term memory storage. Proc Natl Acad Sci USA 1996;93:13445-52.

102. Tanaka H, Samuel CE. Mechanism of interferon action: structure of the mouse PKR gene encoding the interferon-inducible RNA-dependent protein kinase. Proc Natl Acad Sci USA 1994;91:7995-9.

103. Winfree AT. A continuity principle for regeneration. In: Malacinski GM (ed). Pattern Formation. New York: Macmillan; 1984, 106-7.
104. Cotton RT. The ear, nose, oropharynx and larynx. In: Rudolph AM, Hoffman JIE, Rudolph CD (eds). Rudolph's Pediatrics. Stamford: Appleton \& Lange; 1996, 945.

105. Lo CW. The role of gap junction membrane channels in development. J Bioenerg Biomembr 1996;28:379-85.

106. Levin M. Isolation and community: a review of the role of gap-junctional communication in embryonic patterning. $J \mathrm{Membr}$ Biol 2002;185:177-92.

107. Ewart JL, Cohen MF, Meyer RA, Huang GY, Wessels A, Gourdie RG, et al. Heart and neural tube defects in transgenic mice overexpressing the Cx43 gap junction gene. Development 1997; 124:1281-92.

108. Becker DL, McGonnell I, Makarenkova HP, Patel K, Tickle C, Lorimer $\mathbf{J}$, et al. Roles for $\alpha 1$ connexin in morphogenesis of chick embryos revealed using a novel antisense approach. Dev Genet 1999;24:33-42.

109. Chi CL, Martinez S, Wurst W, Martin GR. The isthmic organizer signal FGF8 is required for cell survival in the prospective midbrain and cerebellum. Development 2003;130:2633-44.

110. Toivonen S. Regionalization of the embryo. In: Nakamura O, Toivonen S (eds). Organizer - A Milestone of a Half-Century from Spemann Amsterdam: Elsevier; 1978, 124.

111. Carlson MR, Bryant SV, Gardiner DM. Expression of Msx-2 during development, regeneration, and wound healing in axolotl limbs. J Experimental Zool 1998;282:715-23.

112. Lee D, Malpeli JG. Global form and singularity: Modeling the blind spot's role in lateral geniculate morphogenesis. Science 1994;263:1292-4.

113. Sawai S, Thomason PA, Cox EC. An autoregulatory circuit for long-range self-organization in Dictyostelium cell populations. Nature 2005;433:323-6.

114. Diaz-Benjumea FJ, Cohen SM. Interaction between dorsal and ventral cells in the imaginal disc directs wing development in Drosophila. Cell 1993;75:741-52.

115. Baldry P. Trigger point acupuncture. In: Filshie J, White A (eds). Medical Acupuncture. Edinburgh: Churchill Livingston; 1998, 35.

116. Neumann CJ, Cohen SM. Long-range action of wingless organizes the dorsal-ventral axis of the Drosophila wing. Development 1997; 124:871-80.

117. Xia H, Ben-Amar Baranga A, Hoffman D, Romalis MV. Magnetoencephalography with an atomic magnetometer. Appl Phys Lett 2006;89:211104-6.

118. McCaig CD, Rajnicek AM, Song B, Zhao M. Controlling cell behavior electrically: current views and future potential. Physiol Rev 2005;85:943-78.

119. Azizkhan RG, Caty MG. Teratomas in childhood. Curr Opin Pediatr 1996;8:287-92.

120. Gonzalez-Crussi F. Extragonadal Teratomas. Washington, DC: Armed Forces Institute of Pathology, 1982, 118.

121. Francis RJ, Lo CW. Primordial germ cell deficiency in the connexin 43 knockout mouse arises from apoptosis associated with abnormal p53 activation. Development 2006;133:3451-60.

122. Nichols CR, Timmerman R, Foster RS, Roth BJ, Einhorn LH. Neoplasms of the testis. In: Holland JF, Basst RC Jr., Morton DL, Frei E III, Kufe DW, Weichselbaum RR (eds). Cancer Medicine, 4th edn. Baltimore: Williams \& Wilkins; 1997, 2206.

Received April 19, 2007; accepted July 10, 2007 


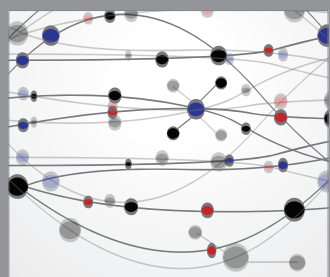

The Scientific World Journal
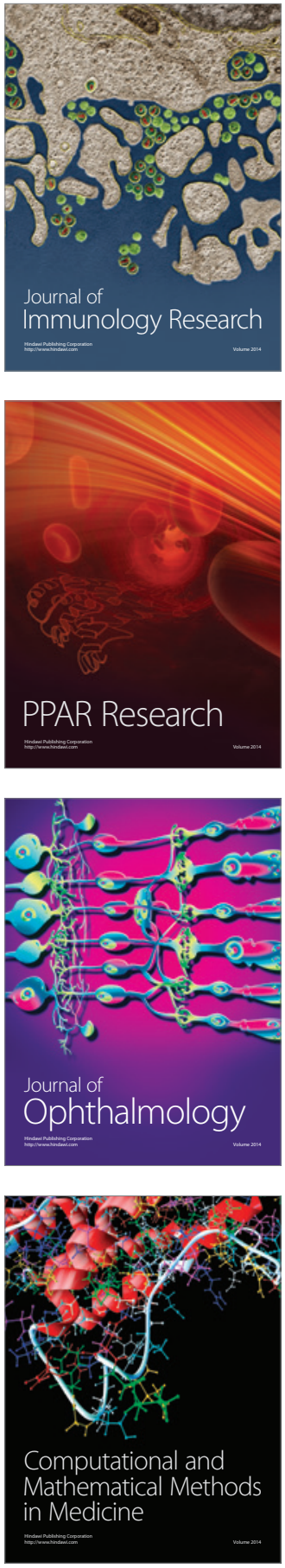

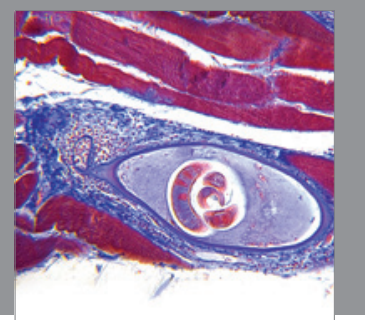

Gastroenterology

Research and Practice
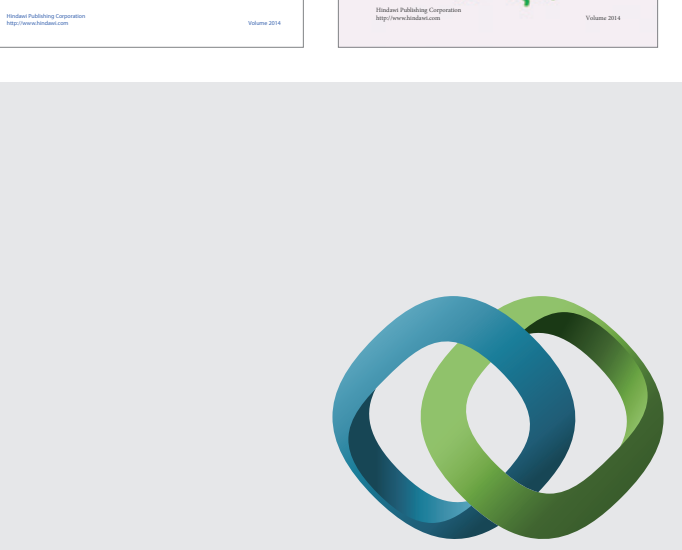

\section{Hindawi}

Submit your manuscripts at

http://www.hindawi.com
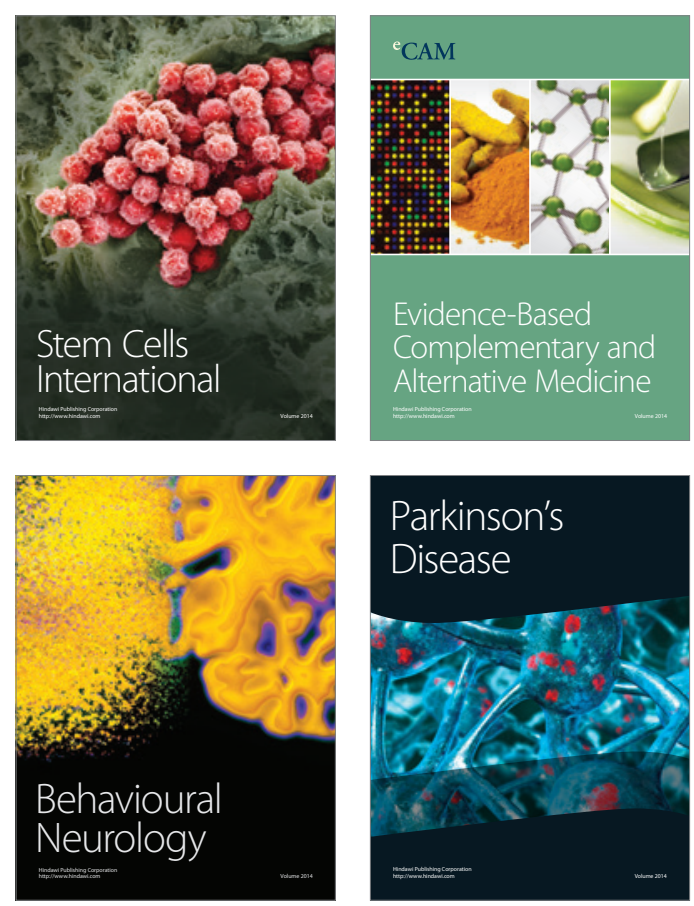

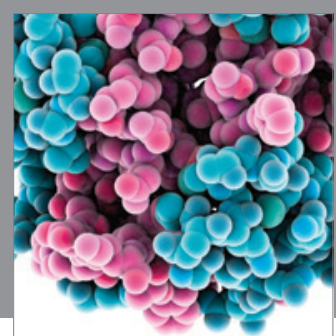

Journal of
Diabetes Research

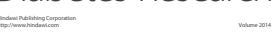

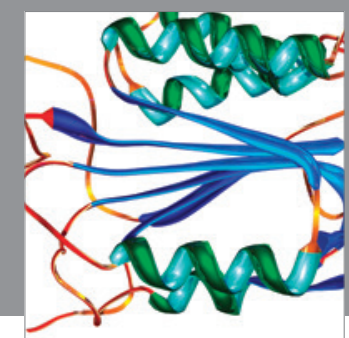

Disease Markers
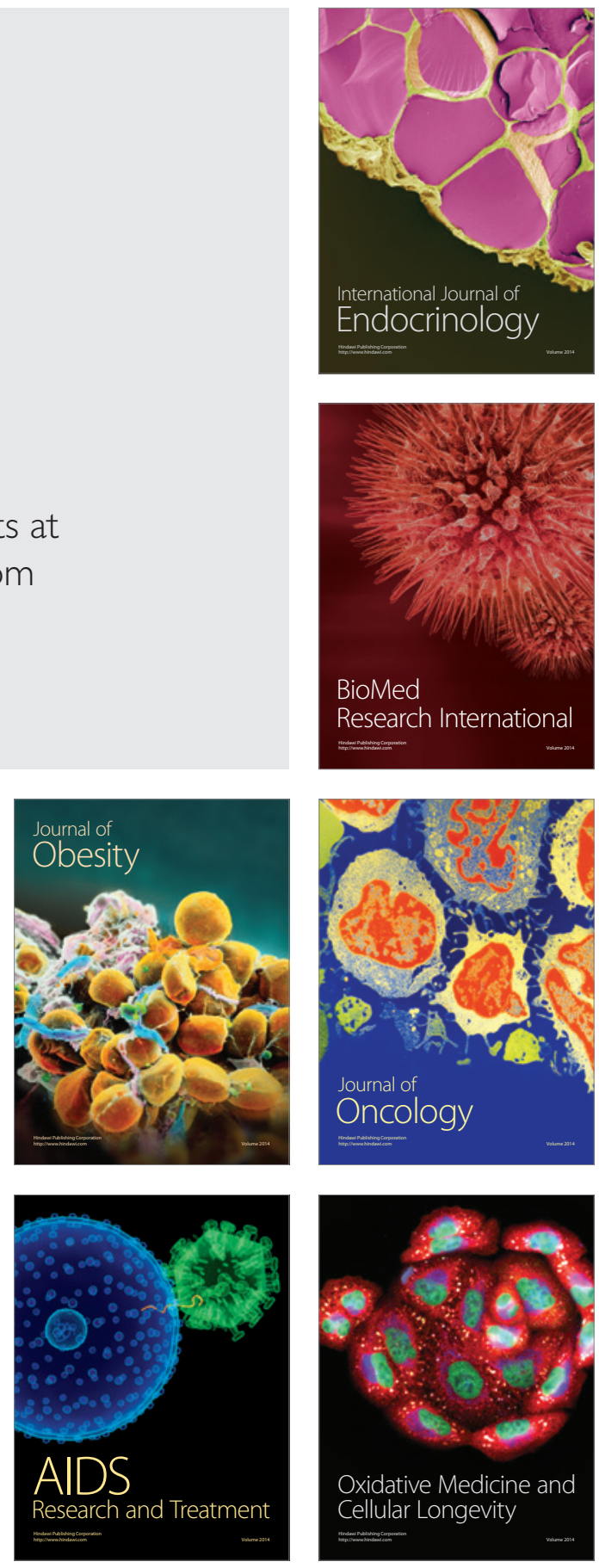